\title{
Prevalence and trends in the childhood dual burden of malnutrition in low- and middle-income countries, 1990-2012
}

\author{
Emma Tzioumis*, Melissa C Kay, Margaret E Bentley and Linda S Adair \\ Department of Nutrition, Gillings School of Global Public Health, University of North Carolina at Chapel Hill, \\ 137 E. Franklin Street, Room 6312, Chapel Hill, NC 27516, USA
}

Submitted 5 March 2015: Final revision received 1 January 2016: Accepted 27 January 2016: First published online 24 February 2016

\begin{abstract}
Objective: To describe trends in country- and individual-level dual burden of malnutrition in children $<5$ years, and age-stratified ( $<2$ years, $\geq 2$ years) countrylevel trends, in thirty-six low- and middle-income countries (LMIC).

Design: Using repeated cross-sectional nationally representative data, we calculated the prevalence of malnutrition (stunting, wasting, overweight) at each survey wave, annualized rates of prevalence change for each country over time, and trends before and after 2000, for all children $<5$ years and separately for those $</ \geq 2$ years. We examined country- (ratio of stunting to overweight) and individual-level (coexistence of stunting and overweight) dual burden in children $<5$ years.

Setting: Demographic and Health Surveys from thirty-six LMIC between 1990 and 2012.

Subjects: Children $<5$ years.

Results: Overall malnutrition prevalence decreased in children $<5$ years, driven by stunting decreases. Stunting rates decreased in $78 \%$ of countries, wasting rates decreased in $58 \%$ of countries and overweight rates increased in $36 \%$ of countries. Rates of change differed for children $</ \geq 2$ years, with children $<2$ years experiencing decreases in stunting in fewer countries yet increases in overweight in more countries. Countries with nearly equal prevalences of stunting and overweight in children $<5$ years increased from 2000 to the final year. Within a country, $0 \cdot 3-10 \cdot 9 \%$ of children $<5$ years were stunted and overweight, and $0 \cdot 6-37 \cdot 8 \%$ of stunted children $<5$ years were overweight.

Conclusions: The dual burden exists in children $<5$ years on both country and individual levels, indicating a shift is needed in policies and programmes to address both sides of malnutrition. Children $<2$ years should be identified as a high-risk demographic.
\end{abstract}

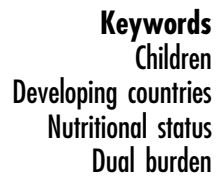

Childhood nutritional diseases are a significant global problem, but the distribution of under- and overnutrition is changing, especially in low- and middle-income countries (LMIC). The various forms of undernutrition (e.g. stunting, wasting, micronutrient deficiencies) in children $<5$ years of age continue to pose a substantial public health concern $^{(1,2)}$, with an estimated 171 million children $<5$ years stunted worldwide in $2010^{(3)}$. As the nutrition transition progresses diets become simultaneously more energy-dense yet nutrient-poor, while lifestyles become more sedentary, leading to overnutrition ${ }^{(4)}$. In 2010, globally, 43 million children $<5$ years were overweight or obese, with an additional 93 million children at risk of overweight $^{(5)}$. Despite sustained economic development in many countries, substantial economic disparities remain within LMIC and nutritional insufficiencies continue even while obesity prevalence is increasing, resulting in a 'dual burden' of malnutrition on the population level ${ }^{(6-8)}$. The dual burden presents a unique and complex public health challenge.

Tracking of population-level anthropometric trends has focused primarily on children $<5$ years of age. WHO and UNICEF commonly report anthropometric indicators for this age group and children $<5$ years are targeted in the Millennium Development Goals ${ }^{(9,10)}$. However, the first 2 years of life have emerged as a critical developmental period, as recognized by the creation of the 1,000 Days initiative $^{(11)}$. A child's linear growth potential is largely determined by this age; thus much of the developmental origins of adult health and human capital work uses linear growth status at 2 years to predict future growth and health $^{(2,12-14)}$. Studies in high-income countries have also 
documented the role of early development of overweight and obesity in the first 2 years of life, since early weight status predicts later weight status and chronic disease risk $^{(15)}$. Recent evidence from a collaboration of five birth cohorts in LMIC also suggests that faster relative weight gain before 2 years is associated with increased risk of overweight in young adults ${ }^{(16)}$. However, the extent of the dual burden in this younger age group has not been estimated. The transition from exclusive breast-feeding to family foods is typically complete around 2 years of age, and appropriate nutrition interventions will differ for children aged $<2$ years and $\geq 2$ years. Therefore, agespecific information is critical when targeting children for nutritional interventions to reduce stunting and, at the same time, prevent overweight and obesity.

Direct comparisons of population-level trends in underand overnutrition in children are scarce, outdated and imprecise. The most recent comprehensive assessment was in 2000, which compared overweight and wasting in children $<5$ years ${ }^{(17)}$. However, more than half of the countries only had one survey, precluding the authors from establishing time trends, and the data came from WHO Country Surveys which vary in quality and representativeness. Since 2000, few explicit comparisons of global trends in child nutrition status have been published. Studies using similar data sources have been published on global trends in stunting $^{(3)}$ and overweight ${ }^{(5)}$, separately. The 2013 Lancet Maternal and Child Nutrition series included a section on childhood anthropometrics ${ }^{(1)}$. However, time trends were aggregated by region, and the country-level data were from a combination of sources and often more than 10 years old. Others have reported on the dual burden in various countries in Latin America, Africa, the Middle East and Asia, but these studies do not use nationally representative data, which limits generalizability and prevents direct comparisons with other countries ${ }^{(18-25)}$. To our knowledge, there are no comparisons of population-level studies of the dual burden in children $(<5$ years) or that distinguish between children aged $<2$ years and $\geq 2$ years.

The current paper documents contemporary trends in the population-level prevalence of stunting, wasting and overweight in children $<5$ years in LMIC, and separately reports these trends for children aged $<2$ years and $\geq 2$ years. We also provide estimates of country-level and individual-level (concurrent stunting and overweight in the same child) dual burden in children $<5$ years. Demographic and Health Surveys (DHS), which are rigorously collected and standardized, provide the necessary data to directly calculate and compare trends across countries and time.

\section{Materials and methods}

\section{Data source and study population}

We use publicly available DHS (available from http:// www.measuredhs.com) data for infants and young children (0-59 months). DHS data derive from nationally representative, household-based surveys of women of reproductive age and their young children ( $0-5$ years). Conducted in more than ninety countries since 1984, they provide data on population health, maternal and child health, and nutrition. DHS respondents are selected with a two-stage sampling process, described elsewhere in detail $^{(26,27)}$. Participant response rates are often over $90 \%{ }^{(26)}$. Interviewers are rigorously trained to ensure reliability, and questionnaires have been standardized and pre-tested to ensure comparability across time and countries ${ }^{(26)}$.

We identified sixty-three LMIC with at least one survey with child anthropometry between 1988 and 2012. To be included in the present analysis, each country had to have at least two surveys with child anthropometry, and at least one survey had to occur in 2005 or later to capture recent trends. Thirty-six countries met these criteria, with survey years from 1990 to 2012, two to eight surveys each, and sample sizes from 1270 to 44827 . Intermediate surveys conducted between the first and final surveys were included when more than two surveys were available. The study population includes all singleton children aged 0-59 months identified in the thirty-six LMIC with a survey since 2005 ( $n$ 839507).

\section{Measures}

Our main variables are height (or length if age $<2$ years), weight, age and sex. All measurements were collected by trained field staff. Standing height ( $>2$ years) or recumbent length $(<2$ years) was measured to the nearest $0 \cdot 1 \mathrm{~cm}$. Weight was measured with a paediatric scale or beam balance scale to the nearest $0 \cdot 1 \mathrm{~kg}$. Stunting and wasting are defined using the conventionally used $Z$-scores for height/length-for-age (HAZ) $<-2$ and weight-for-height/ length (WHZ) <-2, respectively, based on the 2006 WHO Growth Standards ${ }^{(9,28)}$. For comparability, we define overweight using the opposite end of the WHZ distribution: $\mathrm{WHZ}>+2$. This definition of overweight encompasses obesity (WHZ $>+3$ ). However, hereafter we refer to overweight/obesity as overweight. Although some define overweight based on BMI-for-age $Z$-score, the WHZ definition is also used and provides similar estimates of overweight prevalence ${ }^{(5,17)}$.

Countries are classified as low- or middle-income according to the gross national income per capita (Atlas method) from the World Bank ${ }^{(29)}$.

\section{Statistical analysis}

We calculated country-level prevalence of stunting and wasting to represent undernutrition and country-level prevalence of overweight to represent overnutrition. Sample weights were used to estimate nationally representative prevalence and $95 \%$ confidence interval for each indicator among all children $<5$ years, and separately for age groups $<2$ years and $\geq 2$ years ${ }^{(30)}$. We excluded children with missing anthropometry ( $n$ 33372) or 
implausible measurements (HAZ $<-6$ or $>+6$ ( $n$ 19911); WHZ $<-5$ or $>+5$ ( $n$ 16290)). The 1999 Nigeria survey is excluded from our analyses as there are documented measurement issues with the childhood anthropometry data $^{(31)}$. Our final analytic sample size was 773547 .

To compare the overall trends across countries and to account for differences in inter-survey intervals, we calculated the mean annualized change in prevalence between the first and final available surveys for each country $(=$ (final prevalence - first prevalence) $/$ no. of years between the two surveys). Next, we examined annualized change in prevalence in the decades before and after 2000. This choice was both theoretical and practical; the Millennium Development Goals were set forth in 2000 at the Millennium Summit ${ }^{(32)}$ and the majority of countries had a survey in the early 1990s, which allowed us to compare trends in two decades (1990-2000 and 2000-2010). To estimate trends in these two decades, we selected three surveys per country: (i) the survey conducted soonest after the year 1990; (ii) the survey conducted closest to 2000 (either immediately prior to 2000 or after 2000); and (iii) the most recent survey year (final year). We estimated the annualized prevalence changes between surveys (i) and (ii), and between surveys (ii) and (iii). Trends are defined as increasing ( $\geq 0 \cdot 1 \%$ / year), decreasing $(\leq-0 \cdot 1 \% /$ year $)$ or stable (between $-0 \cdot 1$ and $0 \cdot 1 \% /$ year $)^{(5,17)}$. Eight countries did not have a survey before 2000 (Armenia, Cambodia, Congo Brazza, Ethiopia, Gabon, Guinea, Honduras and Lesotho); therefore we estimated trends before 2000 for twenty-eight countries and trends after 2000 for all thirty-six countries. Sensitivity analyses showed that trends did not differ when different numbers of countries were included, so we report estimates for twenty-eight countries in the first decade but thirty-six in the second.

We estimated individual-level burden using two metrics: (i) the percentage of all children who are concurrently stunted and overweight ( $=$ (stunted and overweight children 0-59 months/all children 0-59 months) $\times 100$ ); and (ii) the percentage of stunted children who are also overweight ( $=$ (overweight children 0-59 months/ stunted and overweight children 0-59 months) $\times 100$ ).

Management and descriptive analysis of data as described above were performed in the statistical software package Stata version 12 (2012), using the svy command to account for survey design.

\section{Results}

Selected survey characteristics and country-level prevalence estimates and $95 \%$ confidence intervals for stunting, wasting and overweight in all thirty-six countries at each survey year are shown in the online supplementary material Supplemental Table 1. Stunting, wasting and overweight prevalences varied between countries and over time.
Globally, the combined prevalence of the three distinct forms of childhood malnutrition decreased over time (Fig. 1), driven predominantly by declines in stunting (from $39.3 \%$ to $32 \cdot 2 \%)$. Small reductions in wasting occurred (from $9.9 \%$ to $7.3 \%$ ), while overweight increased (from $4.8 \%$ to $6.0 \%)$.

\section{Annualized changes in prevalence}

Table 1 shows the absolute and annualized changes in country-level prevalence of stunting, wasting and overweight for all children $<5$ years, grouped according to World Bank income group (low $v$. middle income). Overall, the majority of countries decreased stunting prevalence, with annual changes in prevalence ranging from $-0.13 \% /$ year (Mozambique, Cote D'Ivoire) to $-1.29 \% / y e a r$ (Bangladesh). Stunting increased in six countries, five of which were in Africa. Wasting declined in just over half the countries. The magnitudes of annual wasting changes were similar to those of stunting $(-0.10 \% / y e a r$ in Rwanda and Uganda to $-1.03 \% /$ year in Mali). Wasting was stable in eleven countries. Overweight increased in $36 \%$ of countries, with annual increases in these countries ranging from $0.12 \% /$ year (Niger) to $0.74 \% /$ year (Benin). Overweight did not change appreciably in nineteen countries. On average, stunting decreased more in middle-income countries while wasting decreased more in low-income countries. Absolute overweight prevalence increased more in middle-income countries (low income, 0.66\%; middle income, $0.98 \%$ ), but overweight increased slightly more quickly in lowincome countries (low income, 0.07\%/year; middle income, $0.04 \% /$ year).

\section{Time trends before and after the millennium}

Figure 2 displays the annualized changes in country-level prevalence of stunting and overweight for all children $<5$ years, before and after 2000 (listed in descending order of stunting change before 2000 to visually characterize trends in countries of different stunting rates). Inconsistent country-level trends were observed before and after the millennium. Most countries experienced decreases in stunting during both time intervals, and only in Benin did stunting increase both before and after 2000. In four countries (Senegal, Egypt, Namibia and Niger), stunting was decreasing before 2000 but had subsequent increases after 2000. Most countries experienced increases in overweight after 2000, even if they experienced simultaneous increases in stunting (e.g. Benin, Niger, Egypt, Namibia and Guinea).

To determine whether an increase in overweight prevalence occurred simultaneously with a decline in stunting prevalence, we cross-tabulated the stunting and overweight trends (i.e. increase, no change or decrease in prevalence of each indicator; data not shown). Before $2000,36 \%$ of countries experienced a decrease in stunting with concurrent overweight increase. This was the most 
Table 1 Overall absolute and annualized changes in stunting, wasting and overweight from first survey to final survey among children $<5$ years from thirty-six low- and middle-income countries, grouped by World Bank income status

\begin{tabular}{|c|c|c|c|c|c|c|c|}
\hline \multirow[b]{2}{*}{ Country } & \multirow[b]{2}{*}{ Time range } & \multicolumn{2}{|c|}{ Stunting } & \multicolumn{2}{|c|}{ Wasting } & \multicolumn{2}{|c|}{ Overweight } \\
\hline & & $\begin{array}{c}\text { Absolute } \\
\text { change (\%) }\end{array}$ & $\begin{array}{c}\text { Annualized } \\
\text { change (\%/year) }\end{array}$ & $\begin{array}{c}\text { Absolute } \\
\text { change (\%) }\end{array}$ & $\begin{array}{c}\text { Annualized } \\
\text { change (\%/year) }\end{array}$ & $\begin{array}{c}\text { Absolute } \\
\text { change (\%) }\end{array}$ & $\begin{array}{c}\text { Annualized } \\
\text { change (\%/year) }\end{array}$ \\
\hline \multicolumn{8}{|c|}{ Low-income countries } \\
\hline Bangladesh & 1996-2011 & $-19 \cdot 4$ & $-1 \cdot 29$ & $-5 \cdot 2$ & -0.35 & -0.1 & -0.01 \\
\hline Benin & 1996-2006 & 8.4 & 0.84 & $-8 \cdot 6$ & -0.86 & $7 \cdot 4$ & 0.74 \\
\hline Burkina Faso & $1992-2010$ & -5.4 & -0.30 & 0.8 & 0.04 & $-0 \cdot 2$ & -0.01 \\
\hline Cambodia & 2000-2010 & $-10 \cdot 3$ & -1.03 & $-5 \cdot 3$ & -0.53 & $-1 \cdot 8$ & -0.18 \\
\hline Ethiopia & 2000-2011 & $-12 \cdot 8$ & $-1 \cdot 17$ & -2.7 & -0.25 & 0.0 & 0.00 \\
\hline Guinea & 1999-2005 & 4.5 & 0.76 & $1 \cdot 3$ & 0.22 & 1.0 & 0.17 \\
\hline Haiti & 1994-2012 & $-16 \cdot 0$ & -0.89 & $-4 \cdot 0$ & -0.22 & -0.3 & -0.01 \\
\hline Kenya & 1993-2008 & $-4 \cdot 8$ & -0.32 & $-0 \cdot 2$ & -0.01 & -0.9 & -0.06 \\
\hline Malawi & 1992-2010 & -8.5 & -0.47 & -2.5 & -0.14 & $-1 \cdot 1$ & -0.06 \\
\hline Mali & 1995-2006 & 1.5 & 0.14 & -11.4 & -1.03 & $2 \cdot 6$ & 0.24 \\
\hline Mozambique & 1997-2011 & $-1 \cdot 8$ & -0.13 & $-6 \cdot 1$ & -0.43 & $2 \cdot 0$ & 0.14 \\
\hline Nepal & 1996-2011 & $-16 \cdot 6$ & $-1 \cdot 10$ & $-4 \cdot 0$ & -0.27 & 0.5 & 0.03 \\
\hline Niger & 1992-2006 & 6.7 & 0.48 & -5.7 & -0.40 & 1.6 & 0.12 \\
\hline Rwanda & 1992-2010 & $-12 \cdot 0$ & -0.66 & -1.7 & -0.10 & 3.4 & 0.19 \\
\hline Tanzania & 1991-2010 & -8.0 & -0.42 & $-2 \cdot 7$ & -0.14 & -0.3 & -0.01 \\
\hline Uganda & 1995-2011 & $-12 \cdot 5$ & -0.78 & $-1 \cdot 6$ & -0.10 & -1.0 & -0.06 \\
\hline Zimbabwe & 1994-2010 & 3.6 & 0.22 & $-3 \cdot 2$ & -0.20 & -1.5 & -0.10 \\
\hline Average & & $-6 \cdot 1$ & -0.36 & $-3 \cdot 7$ & -0.28 & 0.7 & 0.07 \\
\hline \multicolumn{8}{|c|}{ Middle-income countries } \\
\hline Armenia & 2000-2010 & $1 \cdot 8$ & $0 \cdot 18$ & $1 \cdot 7$ & $0 \cdot 17$ & $-0 \cdot 1$ & -0.01 \\
\hline Bolivia & 1994-2008 & $-6 \cdot 9$ & -0.49 & $-4 \cdot 0$ & -0.29 & 0.5 & 0.04 \\
\hline Cameroon & 1991-2011 & $-4 \cdot 3$ & -0.22 & 1.7 & 0.08 & 1.5 & 0.07 \\
\hline Colombia & $1995-2010$ & $-7 \cdot 3$ & -0.49 & -0.8 & -0.05 & 0.3 & 0.02 \\
\hline Congo Brazza & $2005-2011$ & $-7 \cdot 1$ & $-1 \cdot 18$ & $-2 \cdot 0$ & -0.34 & $-4 \cdot 9$ & -0.81 \\
\hline Cote D'Ivoire & 1994-2011 & $-2 \cdot 2$ & -0.13 & -2.9 & -0.17 & 0.5 & 0.03 \\
\hline $\begin{array}{l}\text { Dominican } \\
\text { Republic }\end{array}$ & 1991-2007 & $-10 \cdot 4$ & -0.65 & 0.1 & 0.01 & $4 \cdot 1$ & 0.26 \\
\hline Egypt & 1992-2008 & -0.8 & -0.05 & $3 \cdot 7$ & 0.23 & 5.9 & 0.37 \\
\hline Gabon & 2000-2012 & -9.5 & -0.79 & -0.7 & -0.06 & 2.5 & 0.21 \\
\hline Ghana & 1993-2008 & $-4 \cdot 7$ & -0.32 & $-5 \cdot 4$ & -0.36 & 2.7 & 0.18 \\
\hline Honduras & 2005-2011 & $-7 \cdot 2$ & $-1 \cdot 20$ & 0.0 & 0.00 & -0.5 & -0.08 \\
\hline India & 1992-2005 & $-9 \cdot 6$ & -0.73 & $-1 \cdot 2$ & -0.09 & -1.0 & -0.08 \\
\hline Jordan & 1990-2009 & -11.4 & -0.60 & -2.5 & -0.13 & -1.9 & -0.10 \\
\hline Lesotho & 2004-2009 & $-5 \cdot 0$ & -1.01 & $-1 \cdot 1$ & -0.22 & 0.9 & 0.17 \\
\hline Namibia & 1992-2006 & $-5 \cdot 0$ & -0.36 & -1.9 & -0.13 & 0.7 & 0.05 \\
\hline Nigeria & 1990-2008 & $-9 \cdot 4$ & -0.52 & $2 \cdot 6$ & 0.14 & $6 \cdot 3$ & 0.35 \\
\hline Peru & 1992-2012 & $-19 \cdot 2$ & -0.96 & $-1 \cdot 1$ & -0.06 & -1.9 & -0.09 \\
\hline Senegal & $1992-2010$ & -4.9 & -0.27 & 0.6 & 0.03 & -1.0 & -0.06 \\
\hline Zambia & 1992-2007 & -0.8 & -0.05 & -0.7 & -0.05 & $4 \cdot 1$ & 0.27 \\
\hline Average & & $-6 \cdot 5$ & -0.52 & -0.7 & -0.07 & $1 \cdot 0$ & 0.04 \\
\hline
\end{tabular}

frequent combination of trends before 2000. After 2000, this pattern occurred in fewer countries (22\%). Instead, a decline in stunting with no change in overweight was the most common combination (33\% of countries).

\section{Age-specific annualized changes in prevalence}

To determine if trends differed by age and sex, we compared country-level prevalence of stunting, wasting and overweight at each country-year in males $<2$ years, males $\geq 2$ years, females $<2$ years and females $\geq 2$ years. Trends did not differ by sex, but they did differ by age (sex-stratified results not shown). We found statistically significant age-group differences in stunting prevalence in $88 \%$ of surveys, in wasting in $90 \%$ of surveys and in overweight in $63 \%$ of surveys, and therefore present agestratified trends.
Age-specific absolute and annualized changes in country-level prevalence of stunting, wasting and overweight across the full time period for which data are available are shown in Table 2, grouped according to World Bank income group. Across both age groups, declines in stunting and wasting were observed in more countries than were increases. Increases in stunting occurred much less often in children $\geq 2$ years (10\% of countries) compared with $<2$ years $36 \%$ of countries). Less than one-tenth of countries experienced a wasting increase in children $<2$ years, whereas a third of countries saw a wasting increase in children $\geq 2$ years. Overweight increased in more countries than it decreased in both age groups. Overweight increased in children $<2$ years in two-thirds of countries, but increased in children $\geq 2$ years in only approximately half of countries. With respect to income group, stunting in children 
$<2$ years decreased more in middle-income countries, whereas it decreased more in low-income countries for children $\geq 2$ years. Wasting decreased more in low- than middle-income countries for both age groups. Greater increases in overweight were observed in low-income

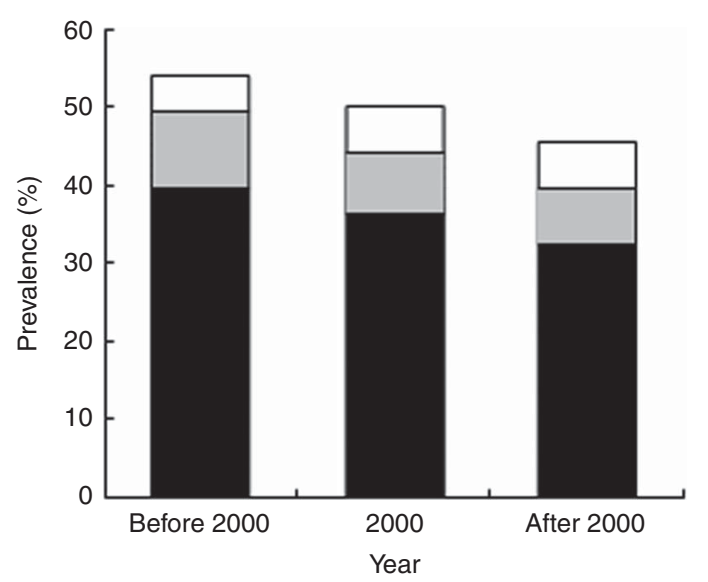

Fig. 1 Cumulative country-level prevalence of stunting ( $\square$ ), wasting $(\square)$ and overweight $(\square)$ at three time points (year closest to 1990, year closest to 2000 and final year) among children $<5$ years from thirty-six low- and middle-income countries, 19902012 countries for children $<2$ years, but not for children $\geq 2$ years, where overweight increased in middle-income countries but decreased in low-income countries.

\section{Age-specific time trends before and after the millennium}

Figure 3(a) and 3(b) show the annualized changes for country-level stunting and overweight before and after 2000 for children $<2$ years and $\geq 2$ years. Countries are listed in descending order by annual changes in stunting before 2000. Both before and after 2000, stunting rates decreased for children $\geq 2$ years in more countries than for children $<2$ years (before 2000, stunting rate decreased in $61 \%$ and $86 \%$ of countries for children $<2$ years and children $\geq 2$ years, respectively; after 2000 , stunting rate decreased in $75 \%$ and $83 \%$ of countries for children $<2$ years and $\geq 2$ years, respectively). Both before and after 2000 , overweight rates increased in children $<2$ years in more countries than for children $\geq 2$ years (before 2000 , overweight rate increased in children $<2$ years in $64 \%$ of countries and in children $\geq 2$ years in $46 \%$ of countries; after 2000 , overweight rate increased in $64 \%$ and $53 \%$ of countries for children $<2$ years and $\geq 2$ years, respectively).

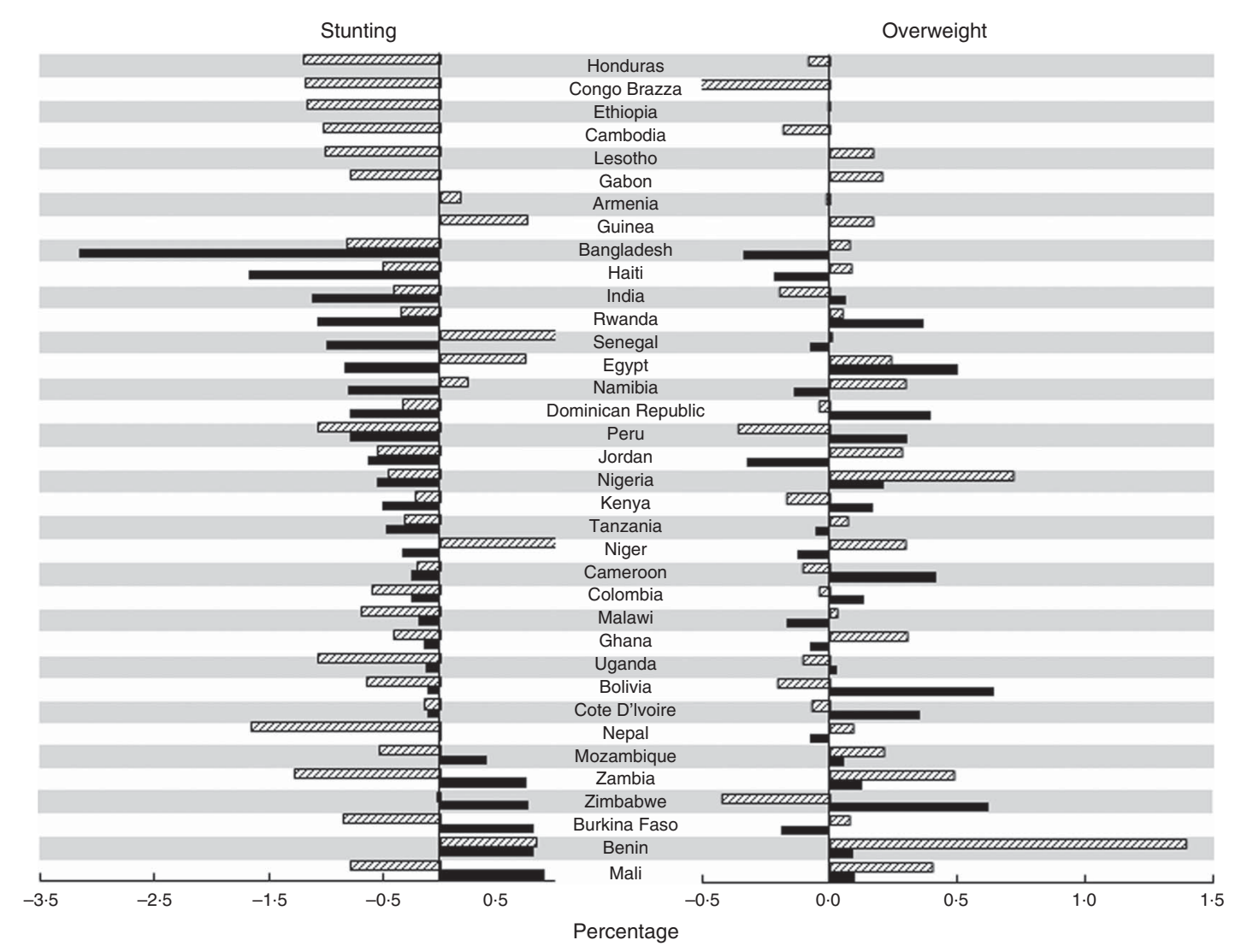

Fig. 2 Annualized change in prevalence of stunting and overweight before and after the millennium ( $\square$, before 2000; $\square$, after 2000) among children $<5$ years from thirty-six low- and middle-income countries, 1990-2012 
Table 2 Age-specific absolute and annualized changes in stunting, wasting and overweight from first survey to final survey among children $<2$ years and children $\geq 2$ years from thirty-six low- and middle-income countries, grouped by World Bank income group

\begin{tabular}{|c|c|c|c|c|c|c|c|c|c|c|c|c|c|}
\hline \multirow[b]{3}{*}{ Country } & \multirow[b]{3}{*}{ Time range } & \multicolumn{4}{|c|}{ Stunting } & \multicolumn{4}{|c|}{ Wasting } & \multicolumn{4}{|c|}{ Overweight } \\
\hline & & \multicolumn{2}{|c|}{$<2$ years } & \multicolumn{2}{|c|}{$\geq 2$ years } & \multicolumn{2}{|c|}{$<2$ years } & \multicolumn{2}{|c|}{$\geq 2$ years } & \multicolumn{2}{|c|}{$<2$ years } & \multicolumn{2}{|c|}{$\geq 2$ years } \\
\hline & & $\begin{array}{c}\text { Absolute } \\
\text { change } \\
(\%)\end{array}$ & $\begin{array}{l}\text { Annualized } \\
\text { change } \\
\text { (\%/year) }\end{array}$ & $\begin{array}{c}\text { Absolute } \\
\text { change } \\
(\%)\end{array}$ & $\begin{array}{c}\text { Annualized } \\
\text { change } \\
\text { (\%/year) }\end{array}$ & $\begin{array}{c}\text { Absolute } \\
\text { change } \\
(\%)\end{array}$ & $\begin{array}{l}\text { Annualized } \\
\text { change } \\
\text { (\%/year) }\end{array}$ & $\begin{array}{c}\text { Absolute } \\
\text { change } \\
(\%)\end{array}$ & $\begin{array}{l}\text { Annualized } \\
\text { change } \\
\text { (\%/year) }\end{array}$ & $\begin{array}{c}\text { Absolute } \\
\text { change } \\
(\%)\end{array}$ & $\begin{array}{l}\text { Annualized } \\
\text { change } \\
\text { (\%/year) }\end{array}$ & $\begin{array}{c}\text { Absolute } \\
\text { change } \\
(\%)\end{array}$ & $\begin{array}{c}\text { Annualized } \\
\text { change } \\
\text { (\%/year) }\end{array}$ \\
\hline \multicolumn{14}{|l|}{ Low-income countries } \\
\hline Bangladesh & 1996-2011 & -13.4 & -0.89 & -23.9 & -1.59 & -13.8 & -0.92 & 0.6 & 0.04 & 0.3 & 0.02 & -0.3 & -0.02 \\
\hline Benin & $1996-2006$ & 10.9 & 1.09 & -9.0 & -0.90 & -8.6 & -0.86 & $-4 \cdot 3$ & -0.43 & $10 \cdot 1$ & 1.01 & 5.0 & 0.50 \\
\hline Burkina Faso & $1992-2010$ & -1.0 & -0.06 & -9.6 & -0.54 & 0.6 & 0.03 & 1.7 & 0.1 .0 & 0.0 & 0.00 & -0.5 & -0.03 \\
\hline Cambodia & $2000-2010$ & $-5 \cdot 1$ & -0.51 & $-12 \cdot 9$ & -1.29 & $-5 \cdot 9$ & -0.59 & -5.0 & -0.50 & $-2 \cdot 9$ & -0.29 & $-1 \cdot 1$ & -0.11 \\
\hline Ethiopia & $2000-2011$ & -14.8 & -1.35 & $-12 \cdot 1$ & $-1 \cdot 10$ & $-4 \cdot 4$ & -0.40 & -1.4 & -0.13 & -0.6 & -0.06 & 0.4 & 0.03 \\
\hline Guinea & 1999-2005 & 2.0 & 0.33 & 7.9 & 1.31 & 0.0 & 0.00 & 1.7 & 0.28 & 1.5 & 0.26 & 0.5 & 0.08 \\
\hline Haiti & $1994-2012$ & $-10 \cdot 6$ & -0.59 & -19.7 & -1.09 & -5.4 & -0.30 & -3.1 & -0.17 & $-1 \cdot 7$ & -0.09 & 0.8 & 0.04 \\
\hline Kenya & 1993-2008 & 0.0 & 0.00 & -8.0 & -0.53 & -1.4 & -0.09 & 0.6 & 0.04 & 0.8 & 0.05 & $-2 \cdot 1$ & -0.14 \\
\hline Malawi & $1992-2010$ & 1.9 & 0.11 & $-19 \cdot 2$ & -1.07 & -3.7 & -0.20 & -0.9 & -0.05 & $2 \cdot 3$ & 0.13 & -3.6 & -0.20 \\
\hline Mali & 1995-2006 & $2 \cdot 7$ & 0.24 & -14.5 & -1.32 & -8.0 & -0.73 & -8.0 & -0.72 & 3.6 & 0.33 & 1.6 & 0.15 \\
\hline Mozambique & $1997-2011$ & $2 \cdot 1$ & 0.15 & -19.5 & -1.39 & $-5 \cdot 2$ & -0.37 & $-3 \cdot 1$ & -0.22 & 4.9 & 0.35 & -1.6 & -0.12 \\
\hline Nepal & $1996-2011$ & -21.9 & -1.46 & -26.8 & -1.79 & -1.6 & -0.11 & -1.3 & -0.09 & 1.3 & 0.08 & -0.1 & 0.00 \\
\hline Niger & $1992-2006$ & 7.3 & 0.52 & 5.0 & 0.36 & $-8 \cdot 1$ & -0.58 & -3.1 & -0.22 & $2 \cdot 3$ & 0.16 & 1.1 & 0.08 \\
\hline Rwanda & $1992-2010$ & -9.6 & -0.54 & -14.8 & -0.82 & -3.6 & -0.20 & -0.2 & -0.01 & 4.6 & 0.26 & $2 \cdot 7$ & 0.15 \\
\hline Tanzania & $1991-2010$ & -5.0 & -0.27 & -11.3 & -0.59 & -2.0 & -0.10 & -3.0 & -0.16 & 1.8 & 0.09 & -1.8 & -0.09 \\
\hline Uganda & $1995-2011$ & $-10 \cdot 9$ & -0.68 & -18.8 & $-1 \cdot 18$ & -0.9 & -0.06 & -0.8 & -0.05 & 0.0 & 0.00 & $-2 \cdot 2$ & -0.14 \\
\hline Zimbabwe & $1994-2010$ & 3.3 & 0.21 & $-5 \cdot 2$ & -0.32 & -2.5 & -0.16 & $-2 \cdot 4$ & -0.15 & -0.2 & -0.01 & -1.6 & -0.10 \\
\hline Average & & $-3 \cdot 7$ & -0.22 & -12.5 & -0.81 & $-4 \cdot 4$ & -0.33 & -1.9 & -0.14 & 1.7 & 0.13 & -0.2 & 0.00 \\
\hline \multicolumn{14}{|l|}{ Middle-income countries } \\
\hline Armenia & $2000-2010$ & 3.4 & 0.34 & 1.1 & 0.11 & 0.2 & 0.02 & $2 \cdot 4$ & 0.24 & $-3 \cdot 7$ & -0.37 & $2 \cdot 2$ & 0.22 \\
\hline Bolivia & $1994-2008$ & -7.9 & -0.56 & $-14 \cdot 1$ & -1.01 & -3.3 & -0.24 & -3.6 & -0.26 & 0.8 & 0.05 & 1.0 & 0.07 \\
\hline Cameroon & $1991-2011$ & -1.5 & -0.08 & $-6 \cdot 4$ & -0.32 & $2 \cdot 2$ & 0.11 & $1 \cdot 1$ & 0.06 & 2.0 & 0.10 & 1.0 & 0.05 \\
\hline Colombia & 1995-2010 & $-1 \cdot 8$ & -0.11 & -11.7 & -0.69 & $-1 \cdot 0$ & -0.06 & $-1 \cdot 2$ & -0.07 & 0.9 & 0.05 & 0.1 & 0.01 \\
\hline Congo Brazza & 2005-2011 & $-4 \cdot 1$ & -0.28 & -9.5 & -0.64 & -0.7 & -0.05 & -0.8 & -0.05 & 0.7 & 0.04 & 0.0 & 0.00 \\
\hline Cote D'lvoire & $1994-2011$ & $-4 \cdot 2$ & -0.70 & $-9 \cdot 2$ & -1.53 & -2.5 & -0.42 & $-1 \cdot 7$ & -0.29 & $-5 \cdot 3$ & -0.89 & -4.5 & -0.76 \\
\hline Dominican Republic & $1991-2007$ & -11.3 & -0.70 & -9.6 & -0.60 & -0.2 & -0.01 & 0.4 & 0.03 & 4.5 & 0.28 & 4.0 & 0.25 \\
\hline Egypt & $1992-2008$ & -1.4 & -0.09 & 0.0 & 0.00 & 2.9 & 0.18 & $4 \cdot 1$ & 0.25 & 7.6 & 0.47 & 4.9 & 0.31 \\
\hline Gabon & $2000-2012$ & $-7 \cdot 2$ & -0.60 & -11.3 & -0.94 & $-2 \cdot 1$ & -0.18 & 0.5 & 0.04 & 3.4 & 0.28 & 1.6 & 0.14 \\
\hline Ghana & $1993-2008$ & -4.8 & -0.32 & $-16 \cdot 6$ & $-1 \cdot 11$ & -1.9 & -0.13 & $-3 \cdot 4$ & -0.23 & $2 \cdot 4$ & 0.16 & 3.4 & 0.23 \\
\hline Honduras & 2005-2011 & $-5 \cdot 8$ & -0.96 & -7.0 & -1.17 & -0.1 & -0.01 & -0.1 & -0.01 & -0.8 & -0.13 & -0.5 & -0.08 \\
\hline India & 1992-2005 & -6.5 & -0.50 & $-17 \cdot 2$ & -1.33 & $-1 \cdot 1$ & -0.08 & 1.7 & 0.13 & -0.4 & -0.03 & $-1 \cdot 3$ & -0.10 \\
\hline Jordan & $1990-2009$ & $-10 \cdot 2$ & -0.53 & $-12 \cdot 2$ & -0.64 & $-3 \cdot 3$ & -0.17 & -1.9 & -0.10 & -3.4 & -0.18 & -0.9 & -0.05 \\
\hline Lesotho & 2004-2009 & -6.3 & -1.26 & -3.6 & -0.72 & $-2 \cdot 1$ & -0.41 & -0.4 & -0.08 & 2.0 & 0.40 & -0.3 & -0.06 \\
\hline Namibia & $1992-2006$ & $-6 \cdot 9$ & -0.50 & -3.4 & -0.24 & -0.6 & -0.04 & -3.0 & -0.21 & 0.9 & 0.06 & 0.7 & 0.05 \\
\hline Nigeria & $1990-2008$ & 0.7 & 0.04 & $-17 \cdot 8$ & -0.99 & 2.7 & 0.15 & $2 \cdot 7$ & 0.15 & 7.8 & 0.43 & $5 \cdot 4$ & 0.30 \\
\hline Peru & $1992-2012$ & -7.8 & -0.39 & -26.6 & -1.33 & $-1 \cdot 7$ & -0.08 & -0.8 & -0.04 & -1.5 & -0.07 & $-2 \cdot 1$ & -0.11 \\
\hline Senegal & $1992-2010$ & 1.0 & 0.06 & -9.4 & -0.52 & -1.5 & -0.08 & $2 \cdot 2$ & 0.12 & -1.4 & -0.08 & -0.6 & -0.03 \\
\hline Zambia & $1992-2007$ & 1.5 & 0.10 & $-3 \cdot 8$ & -0.25 & -0.9 & -0.06 & $-0 . \overline{3}$ & -0.02 & $6 \cdot 1$ & 0.40 & 2.6 & 0.17 \\
\hline Average & & $-4 \cdot 3$ & -0.37 & -9.9 & -0.73 & -0.8 & -0.08 & -0.1 & -0.02 & 1.2 & 0.05 & 0.9 & 0.03 \\
\hline
\end{tabular}


(a)

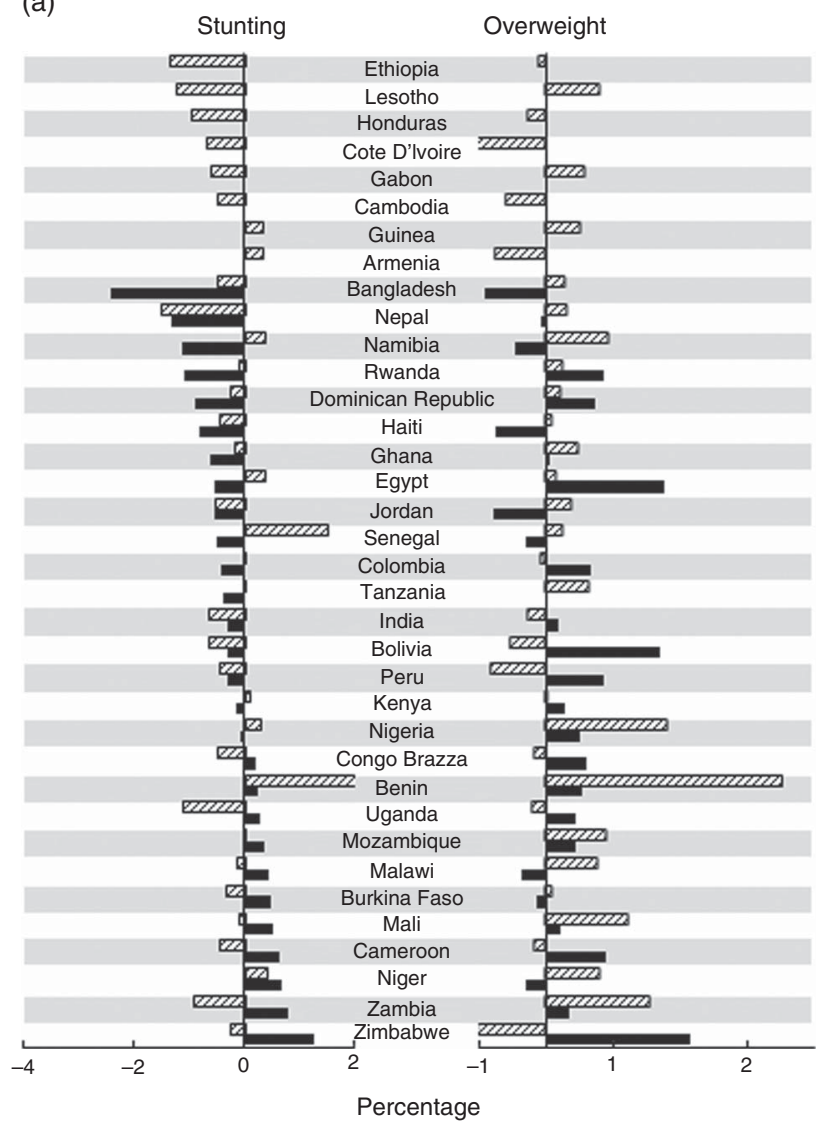

(b)

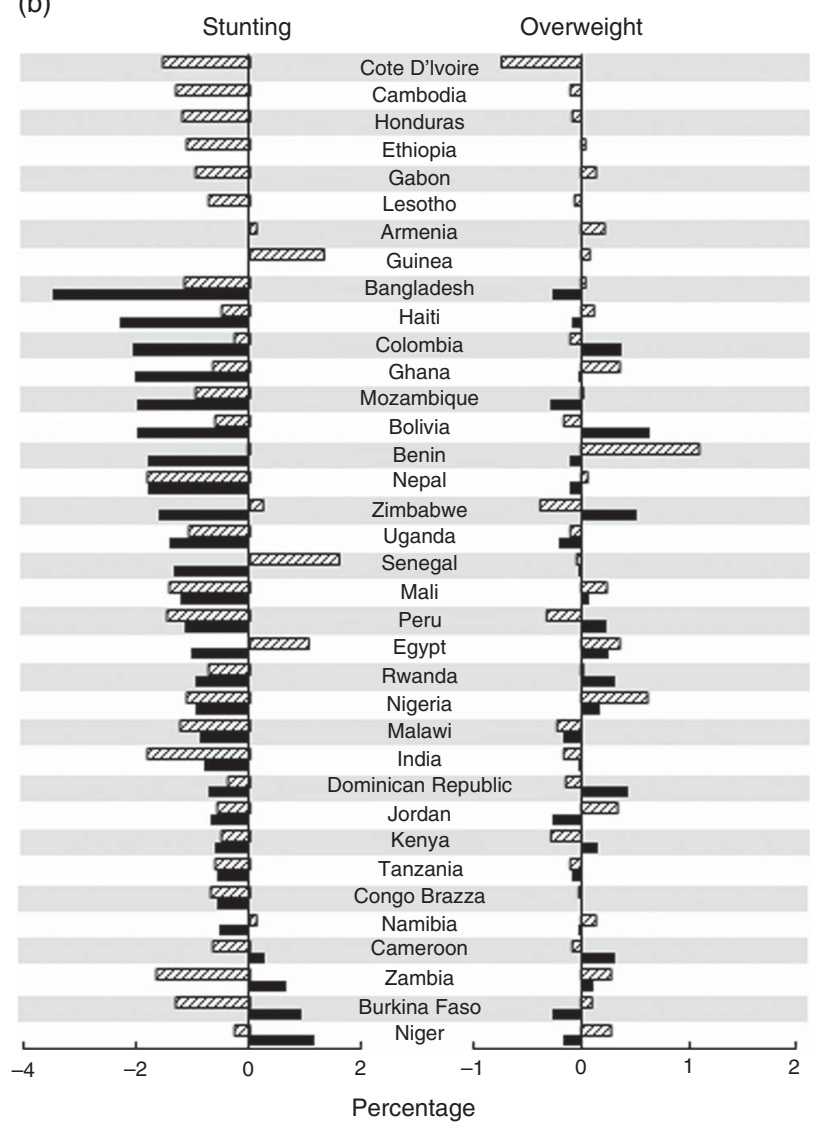

Fig. 3 Age-specific annualized change in prevalence of stunting and overweight before and after the millennium ( $\square$, before 2000; $\square$, after 2000) among children $<2$ years (a) and children $\geq 2$ years (b) from thirty-six low- and middle-income countries, 1990-2012

\section{Dual burden}

Figure 4 shows countries ranked by their ratio of countrylevel stunting to overweight prevalence at the millennium and at the most recent survey. No countries had a ratio less than 1, which would indicate higher overweight than stunting prevalence. Three countries (Armenia, Egypt and the Dominican Republic) had a ratio close to 1 in 2000, indicating nearly equal prevalences of stunting and overweight. Those same three countries, plus Jordan, had ratios close to 1 in the final year. The maximum ratio in 2000 was 99.02 (Nepal), but was much lower in the final year (27.46, Nepal).

We examined individual-level dual burden for each country at each year by cross-tabulating stunting and overweight status within children, grouped according to World Bank income group (Table 3). The percentage of children $<5$ years within a country who were stunted and overweight ranged from $0 \cdot 31 \%$ (Nepal, 2006) to 10.87\% (Egypt, 2008). Ten per cent of country-years had $>5 \%$ of children affected by both stunting and overweight. The percentage of stunted children within a country who were also overweight ranged from $0 \cdot 61 \%$ (Nepal, 2006) to $37 \cdot 82 \%$ (Egypt, 2008). Sixtytwo per cent of country-years had $>5 \%$ of stunted children also affected by overweight. Compared with low-income countries, middle-income countries had higher proportions of children who were stunted and overweight, as well as stunted children who were overweight.

\section{Discussion}

The present study is the first to directly compare prevalence of stunting, wasting and overweight in children $<5$ years, to estimate the dual burden of malnutrition in children $<5$ years, and to examine differences between children $<2$ years and $\geq 2$ years for multiple LMIC. Our findings suggest that overall malnutrition is decreasing in children $<5$ years, but trends varied for the three individual forms of malnutrition. Stunting has been the focus of many international efforts and programmes and as a result has declined but remains high, especially in sub-Saharan Africa and South-East Asia. Unfortunately, declines in stunting are occurring alongside increases in overweight among young children in many settings. Consequently, the dual burden is becoming a reality in an increasing number of countries, particularly middle-income countries.

Globally, stunting decreased by similar magnitude before 2000 and after 2000 in children $<5$ years. Average 


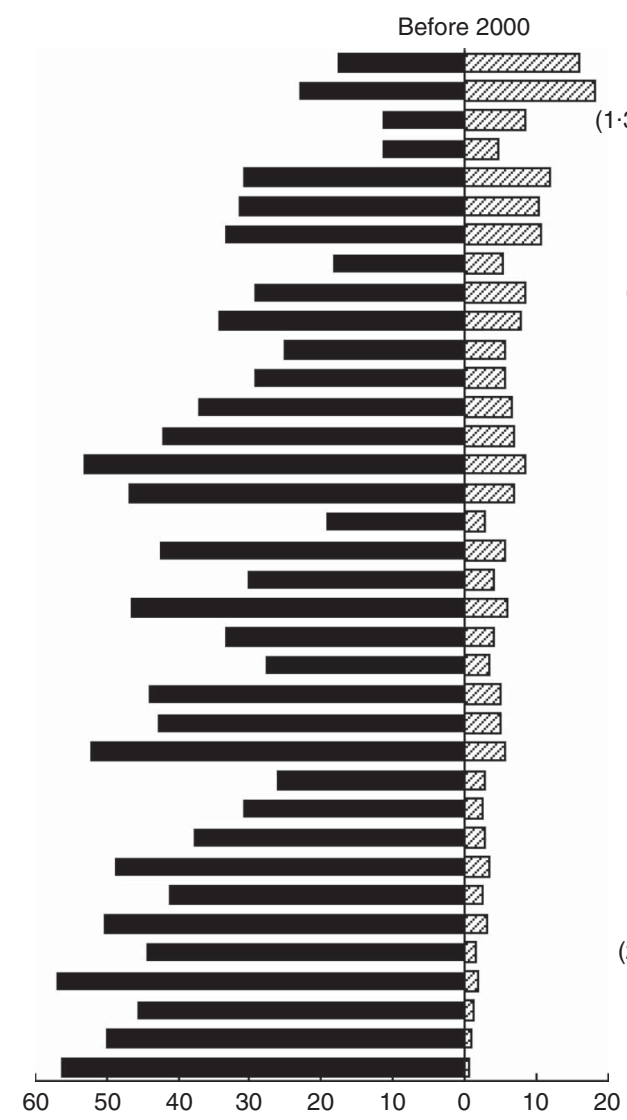

(1.11) Armenia (1.23)

$(1 \cdot 28)$ Egypt $(1 \cdot 45)$

(1-35) Dominican Republic (1-19)

(2.54) Jordan (1.19)

(2.62) Peru (2.41)

(3.09) Zimbabwe (5.64)

(3.16) Bolivia (3.16)

(3.53) Colombia (2.57)

(3.54) Congo Brazza (6.55)

(4.44) Cameroon (5.03)

(4.52) Gabon (1.97)

$(5 \cdot 11)$ Honduras (4.23)

$(5 \cdot 57)$ Kenya (7.06)

(6.11) Lesotho (4.79)

(6.43) Malawi (5.42)

(6.91) Rwanda (5.99)

(7.38) Senegal (10.33)

(7.52) Nigeria (4.35)

(7.55) Cote D'lvoire (9.29)

(7.80) Mozambique (5.54)

(8.42) Guinea (7.64)

$(8 \cdot 48)$ Namibia $(5 \cdot 76)$

(8.60) Uganda (8.12)

(8.61) Tanzania (7.56)

(9.43) Zambia (5.28)

(9.64) Haiti (5.39)

(12.80) Ghana (4.92)

(13.31) Benin (4.28)

(13.73) Cambodia (22.11)

(16.36) Mali (8.24)

(16.92) India (30.13)

(27.13) Burkina Faso (13.48)

(29.89) Ethiopia (23.76)

(40.87) Niger (15.57)

(63.41) Bangladesh (23.90)

(99.02) Nepal (27.49)

Percentage

Fig. 4 Comparison of estimations of the country-level dual burden (ratio of stunting prevalence to overweight prevalence) in the year closest to 2000 and the most recent year after 2000 among children $<5$ years from thirty-six low- and middle-income countries, 1990-2012. Countries are ranked according to the dual burden ratio in the year closest to 2000 ( $\square$, stunting prevalence; $\square$, overweight prevalence)

annual change in stunting prevalence before 2000 was $-0.37 \% /$ year and annual change after the millennium was slightly more pronounced (-0.41\%/year). Reductions in wasting occurred before 2000 (average annual change of $-0.39 \% /$ year), but plateaued after the millennium $(-0.06 \% / y e a r)$. Overweight increased similarly before and after 2000 , with average annual changes of $0 \cdot 10 \%$ /year and $0.08 \% /$ year, respectively. The stunting trends indicate steady, but not accelerating progress, whereas wasting flatlined after 2000. The trends reported here are similar to findings from country-specific analyses in $\mathrm{LMIC}^{(33-35)}$ and in recent global assessments of preschool children ${ }^{(3,5,36)}$. Variability across countries may reflect differences in breast-feeding practices, the time of introduction to and quality of complementary foods, urban $v$. rural environment and family wealth ${ }^{(33,37-39)}$. Given the widespread focus on the Millennium Development Goals and global investment in reducing childhood undernutrition, this is disappointing. The combination of increases in overweight with a decelerating reduction in stunting and wasting paints an even more worrisome picture, and is slowly gaining attention ${ }^{(40,41)}$. These opposing individual trends mirror the results of our estimation of the dual burden, with more countries manifesting the dual burden over time.

A key contribution of our work is the exploration of trends before and after age 2 years, which have not been investigated previously. A child's second birthday has been identified as a critical milestone in physical and cognitive development; therefore gaining awareness of the trends in this age group is important ${ }^{(42)}$. In our study, we showed differences between children $<2$ years and $\geq 2$ years, with children $<2$ years in a worse situation regarding both under- and overnutrition. Stunting decreased more in children $\geq 2$ years than in children $<2$ years both before and after 2000. Stunting continued to increase in children $<2$ years in one-third of countries after 2000, whereas few increases were seen after 2000 in children $\geq 2$ years. Overweight rates increased in both age groups, but the rates increased in more countries for children $<2$ years than $\geq 2$ years before and after 2000 . Additionally, the magnitude of changes was more extreme in children $<2$ years compared with those $\geq 2$ years.

Given how critical the window from birth to age 2 years is for future growth and development, it is concerning that children in this age group have poorer indicators than 
Table 3 Number and proportion experiencing individual-level dual burden in each country-year among children $<5$ years from thirty-six low- and middle-income countries, grouped by World Bank income group

\begin{tabular}{|c|c|c|c|c|c|c|}
\hline & Year & No. total & No. stunted & $\begin{array}{l}\text { No. stunted and } \\
\text { overweight }\end{array}$ & $\begin{array}{c}\% \text { stunted and } \\
\text { overweight }\end{array}$ & $\begin{array}{c}\% \text { of stunted who } \\
\text { are overweight }\end{array}$ \\
\hline \multicolumn{7}{|c|}{ Low-income countries } \\
\hline \multirow[t]{5}{*}{ Bangladesh } & 1996 & 4674 & 2783 & 62 & 1.3 & $2 \cdot 2$ \\
\hline & 1999 & 5294 & 2605 & 26 & 0.5 & 1.0 \\
\hline & 2004 & 5871 & 2870 & 28 & 0.5 & 1.0 \\
\hline & 2007 & 5250 & 2247 & 19 & 0.4 & 0.8 \\
\hline & 2011 & 7549 & 3003 & 52 & 0.7 & 1.7 \\
\hline \multirow[t]{3}{*}{ Benin } & 1996 & 2443 & 835 & 38 & 1.6 & 4.6 \\
\hline & 2001 & 4241 & 1617 & 58 & 1.4 & 3.6 \\
\hline & 2006 & 11878 & 4994 & 854 & 7.2 & $17 \cdot 1$ \\
\hline \multirow{4}{*}{ Burkina Faso } & 1992 & 4309 & 1559 & 57 & 1.3 & 3.7 \\
\hline & 1998 & 4485 & 1937 & 38 & 0.8 & $2 \cdot 0$ \\
\hline & 2003 & 7954 & 3405 & 238 & 3.0 & 7.0 \\
\hline & 2010 & 6352 & 2147 & 97 & 1.5 & 4.5 \\
\hline \multirow[t]{3}{*}{ Cambodia } & 2000 & 3486 & 1753 & 95 & $2 \cdot 7$ & 5.4 \\
\hline & 2005 & 3538 & 1557 & 30 & 0.8 & 1.9 \\
\hline & 2010 & 3660 & 1449 & 45 & 1.2 & $3 \cdot 1$ \\
\hline \multirow[t]{3}{*}{ Ethiopia } & 2000 & 8659 & 4602 & 98 & $1 \cdot 1$ & $2 \cdot 1$ \\
\hline & 2005 & 3815 & 1786 & 95 & 2.5 & $5 \cdot 3$ \\
\hline & 2011 & 9398 & 3958 & 85 & 0.9 & $2 \cdot 1$ \\
\hline \multirow{2}{*}{ Guinea } & 1999 & 4232 & 1413 & 88 & $2 \cdot 1$ & $6 \cdot 2$ \\
\hline & 2005 & 2528 & 966 & 69 & $2 \cdot 7$ & $7 \cdot 1$ \\
\hline \multirow{4}{*}{ Haiti } & 1994 & 2708 & 972 & 48 & 1.8 & 4.9 \\
\hline & 2000 & 5410 & 1502 & 41 & 0.8 & $2 \cdot 7$ \\
\hline & 2005 & 2500 & 712 & 46 & 1.8 & 6.5 \\
\hline & 2012 & 3894 & 846 & 45 & 1.2 & $5 \cdot 3$ \\
\hline \multirow[t]{4}{*}{ Kenya } & 1993 & 4814 & 1875 & 107 & $2 \cdot 2$ & 5.7 \\
\hline & 1998 & 4478 & 1691 & 140 & $3 \cdot 1$ & $8 \cdot 3$ \\
\hline & 2003 & 4608 & 1558 & 105 & $2 \cdot 3$ & $6 \cdot 7$ \\
\hline & 2008 & 4981 & 1680 & 135 & $2 \cdot 7$ & 8.0 \\
\hline \multirow[t]{4}{*}{ Malawi } & 1992 & 3109 & 1607 & 185 & $6 \cdot 0$ & 11.5 \\
\hline & 2000 & 8924 & 4554 & 484 & 5.4 & $10 \cdot 6$ \\
\hline & 2004 & 7931 & 4087 & 536 & $6 \cdot 8$ & 13.1 \\
\hline & 2010 & 4457 & 2028 & 230 & $5 \cdot 2$ & 11.3 \\
\hline \multirow[t]{3}{*}{ Mali } & 1995 & 4614 & 1668 & 48 & 1.0 & 2.9 \\
\hline & 2001 & 9170 & 3821 & 136 & 1.5 & 3.6 \\
\hline & 2006 & 10684 & 4015 & 277 & $2 \cdot 6$ & 6.9 \\
\hline \multirow[t]{3}{*}{ Mozambique } & 1997 & 3346 & 1474 & 113 & 3.4 & 7.7 \\
\hline & 2003 & 7827 & 3538 & 209 & $2 \cdot 7$ & 5.9 \\
\hline & 2011 & 9071 & 3517 & 412 & 4.5 & 11.7 \\
\hline Nepal & 1996 & 3706 & 2090 & 21 & 0.6 & 1.0 \\
\hline & 2001 & 6144 & 3465 & 24 & 0.4 & 0.7 \\
\hline & 2006 & 5190 & 2604 & 16 & 0.3 & 0.6 \\
\hline & 2011 & 2130 & 965 & 15 & 0.7 & 1.6 \\
\hline Niger & 1992 & 4591 & 1996 & 49 & $1 \cdot 1$ & 2.5 \\
\hline & 1998 & 3816 & 1693 & 19 & 0.5 & $1 \cdot 1$ \\
\hline & 2006 & 3595 & 1776 & 79 & $2 \cdot 2$ & 4.4 \\
\hline Rwanda & 1992 & 4261 & 2305 & 91 & $2 \cdot 1$ & 3.9 \\
\hline & 2000 & 5958 & 2714 & 243 & $4 \cdot 1$ & $9 \cdot 0$ \\
\hline & 2005 & 3584 & 1767 & 137 & $3 \cdot 8$ & $7 \cdot 8$ \\
\hline & 2010 & 3984 & 1723 & 150 & $3 \cdot 8$ & 8.7 \\
\hline Tanzania & 1991 & 6274 & 3129 & 222 & 3.5 & $7 \cdot 1$ \\
\hline & 1996 & 5176 & 2542 & 117 & $2 \cdot 3$ & 4.6 \\
\hline & 2004 & 6940 & 2904 & 164 & $2 \cdot 4$ & $5 \cdot 6$ \\
\hline & 2010 & 6646 & 2605 & 183 & $2 \cdot 8$ & 7.0 \\
\hline Uganda & 1995 & 4466 & 1845 & 104 & $2 \cdot 3$ & $5 \cdot 6$ \\
\hline & 2000 & 5038 & 2178 & 141 & 2.8 & 6.5 \\
\hline & 2006 & 2322 & 890 & 44 & 1.9 & 4.9 \\
\hline & 2011 & 2025 & 636 & 35 & $1 \cdot 7$ & $5 \cdot 5$ \\
\hline Zimbabwe & 1994 & 2048 & 581 & 47 & $2 \cdot 3$ & 8.1 \\
\hline & 1999 & 2590 & 808 & 129 & $5 \cdot 0$ & $16 \cdot 0$ \\
\hline & 2005 & 3833 & 1249 & 170 & 4.4 & 13.6 \\
\hline & 2010 & 4226 & 1341 & 104 & 2.5 & $7 \cdot 8$ \\
\hline Average & & & & & $2 \cdot 3$ & $5 \cdot 7$ \\
\hline Middle-income c & & & & & & \\
\hline Armenia & 2000 & 1495 & 263 & 63 & $4 \cdot 2$ & $24 \cdot 0$ \\
\hline & 2005 & 1202 & 170 & 37 & 3.1 & 21.8 \\
\hline & 2010 & 1318 & 282 & 104 & 7.9 & 36.9 \\
\hline
\end{tabular}


Table 3 Continued

\begin{tabular}{|c|c|c|c|c|c|c|}
\hline & Year & No. total & No. stunted & $\begin{array}{l}\text { No. stunted and } \\
\text { overweight }\end{array}$ & $\begin{array}{l}\% \text { stunted and } \\
\text { overweight }\end{array}$ & $\begin{array}{l}\% \text { of stunted who } \\
\text { are overweight }\end{array}$ \\
\hline \multirow[t]{4}{*}{ Bolivia } & 1994 & 2882 & 972 & 93 & $3 \cdot 2$ & $9 \cdot 6$ \\
\hline & 1998 & 6147 & 2214 & 286 & 4.7 & $12 \cdot 9$ \\
\hline & 2003 & 9053 & 3014 & 348 & 3.8 & 11.5 \\
\hline & 2008 & 7636 & 2011 & 186 & 2.4 & $9 \cdot 2$ \\
\hline \multirow{4}{*}{ Cameroon } & 1991 & 2556 & 824 & 35 & 1.4 & 4.2 \\
\hline & 1998 & 1756 & 572 & 49 & $2 \cdot 8$ & $8 \cdot 6$ \\
\hline & 2004 & 3090 & 1072 & 122 & 3.9 & 11.4 \\
\hline & 2011 & 4845 & 1516 & 121 & 2.5 & 8.0 \\
\hline \multirow{4}{*}{ Colombia } & 1995 & 4466 & 871 & 41 & 0.9 & 4.7 \\
\hline & 2000 & 4120 & 760 & 34 & 0.8 & 4.5 \\
\hline & 2005 & 12239 & 1919 & 49 & 0.4 & 2.6 \\
\hline & 2010 & 15773 & 2259 & 82 & 0.5 & 3.6 \\
\hline \multirow[t]{2}{*}{ Congo Brazza } & 2005 & 3809 & 1059 & 192 & 5.0 & $18 \cdot 1$ \\
\hline & 2011 & 4323 & 1129 & 65 & 1.5 & $5 \cdot 8$ \\
\hline \multirow[t]{3}{*}{ Cote D'Ivoire } & 1994 & 3333 & 1008 & 32 & 1.0 & 3.2 \\
\hline & 1998 & 1506 & 416 & 33 & 2.2 & $7 . \overline{9}$ \\
\hline & 2011 & 3086 & 900 & 42 & 1.4 & 4.7 \\
\hline \multirow[t]{4}{*}{ Dominican Republic } & 1991 & 3133 & 758 & 37 & 1.2 & 4.9 \\
\hline & 1996 & 3647 & 567 & 22 & 0.6 & 3.9 \\
\hline & 2002 & 9117 & 1136 & 107 & $1 \cdot 2$ & 9.4 \\
\hline & 2007 & 9093 & 1019 & 107 & 1.2 & 10.5 \\
\hline \multirow[t]{6}{*}{ Egypt } & 1992 & 7241 & 2004 & 313 & 4.3 & $15 \cdot 6$ \\
\hline & 1995 & 10165 & 3477 & 679 & $6 \cdot 7$ & 19.5 \\
\hline & 2000 & 10078 & 2279 & 717 & $7 \cdot 1$ & 31.5 \\
\hline & 2003 & 5911 & 1147 & 222 & $3 \cdot 8$ & 19.4 \\
\hline & 2005 & 12038 & 3167 & 1092 & $9 \cdot 1$ & 34.5 \\
\hline & 2008 & 9275 & 2665 & 1008 & $10 \cdot 9$ & $37 \cdot 8$ \\
\hline \multirow[t]{2}{*}{ Gabon } & 2000 & 3386 & 978 & 60 & 1.8 & $6 \cdot 1$ \\
\hline & 2012 & 3222 & 744 & 82 & 2.5 & 11.0 \\
\hline \multirow[t]{4}{*}{ Ghana } & 1993 & 1825 & 578 & 16 & 0.9 & $2 \cdot 8$ \\
\hline & 1998 & 2664 & 873 & 28 & 1.1 & 3.2 \\
\hline & 2003 & 2987 & 1077 & 67 & $2 \cdot 2$ & $6 \cdot 2$ \\
\hline & 2008 & 2293 & 625 & 58 & 2.5 & $9 \cdot 3$ \\
\hline \multirow{2}{*}{ Honduras } & 2005 & 9092 & 3196 & 99 & 1.1 & 3.1 \\
\hline & 2011 & 9841 & 2519 & 73 & 0.7 & 2.9 \\
\hline \multirow[t]{3}{*}{ India } & 1992 & 26786 & 14411 & 536 & 2.0 & 3.7 \\
\hline & 1998 & 24892 & 12033 & 607 & $2 \cdot 4$ & 5.0 \\
\hline & 2005 & 40963 & 17748 & 534 & 1.3 & 3.0 \\
\hline \multirow{5}{*}{ Jordan } & 1990 & 6519 & 1327 & 186 & 2.9 & 14.0 \\
\hline & 1997 & 5490 & 652 & 60 & $1 \cdot 1$ & $9 \cdot 2$ \\
\hline & 2002 & 4745 & 635 & 49 & 1.0 & $7 \cdot 7$ \\
\hline & 2007 & 4312 & 662 & 190 & 4.4 & 28.7 \\
\hline & 2009 & 4236 & 428 & 53 & 1.3 & $12 \cdot 4$ \\
\hline Lesotho & 2004 & 1351 & 591 & 49 & $3 \cdot 6$ & 8.3 \\
\hline & 2009 & 1580 & 618 & 53 & 3.4 & $8 \cdot 6$ \\
\hline Namibia & 1992 & 2511 & 870 & 50 & $2 \cdot 0$ & $5 \cdot 7$ \\
\hline & 2000 & 2875 & 776 & 47 & 1.6 & $6 \cdot 1$ \\
\hline & 2006 & 3603 & 1059 & 63 & $1 \cdot 7$ & 5.9 \\
\hline Nigeria & 1990 & 5705 & 2655 & 85 & 1.5 & $3 \cdot 2$ \\
\hline & 2003 & 4275 & 1763 & 151 & 3.5 & $8 \cdot 6$ \\
\hline & 2008 & 18660 & 7811 & 1160 & $6 \cdot 2$ & 14.9 \\
\hline Peru & 1992 & 7607 & 2939 & 242 & $3 \cdot 2$ & $8 \cdot 2$ \\
\hline & 1996 & 14708 & 5192 & 415 & $2 \cdot 8$ & 8.0 \\
\hline & 2000 & 11475 & 3966 & 412 & $3 \cdot 6$ & $10 \cdot 4$ \\
\hline & 2005 & 2269 & 734 & 47 & $2 \cdot 1$ & $6 \cdot 4$ \\
\hline & 2007 & 2346 & 774 & 49 & $2 \cdot 1$ & $6 \cdot 3$ \\
\hline & 2008 & 5646 & 1567 & 104 & 1.8 & $6 \cdot 6$ \\
\hline & 2011 & 8625 & 2034 & 56 & 0.6 & $2 \cdot 8$ \\
\hline & 2012 & 9071 & 1864 & 46 & 0.5 & 2.5 \\
\hline Senegal & 1992 & 4419 & 1431 & 62 & 1.4 & $4 \cdot 3$ \\
\hline & 2005 & 2808 & 584 & 19 & 0.7 & 3.3 \\
\hline & 2010 & 3606 & 1079 & 58 & 1.6 & 5.4 \\
\hline Zambia & 1992 & 4811 & 2236 & 101 & $2 \cdot 1$ & 4.5 \\
\hline & 1996 & 5373 & 2657 & 193 & $3 \cdot 6$ & $7 \cdot 3$ \\
\hline & 2001 & 5324 & 2816 & 188 & 3.5 & $6 \cdot 7$ \\
\hline & 2007 & 4947 & 2150 & 271 & 5.5 & $12 \cdot 6$ \\
\hline Average & & & & & $2 \cdot 7$ & 9.9 \\
\hline
\end{tabular}


older children. The limited recovery from stunting after 2 years has led to prioritization of efforts to reduce stunting in children $<2$ years ${ }^{(43,44)}$. Overweight/obesity in this age group also deserves attention, because although overweight tends to persist and becomes more prevalent towards adolescence and adulthood, rapid growth and weight gain in infancy have been identified as risk factors for subsequent overweight in childhood $^{(45-49)}$ and adult body composition ${ }^{(13,50-52)}$. Since this is a cumulative problem, it is important to identify at-risk children as early as possible to avoid initializing the chain of events. Additionally, interventions that target only undernutrition, especially those that promote 'catch-up' growth, may unintentionally contribute to overweight/obesity ${ }^{(53)}$. This has been documented in a supplementary feeding programme in Chile that led to increased childhood overweight and in the Oportunidades conditional cash transfer in Mexico which increased adult overweight, obesity and blood pressure ${ }^{(54,55)}$. Targeting children $<2$ years in both stunting and overweight interventions provides an opportunity for renewed progress to be made in improving childhood nutrition in a climate where improvements have plateaued.

The country-level dual burden ratios for children $<5$ years presented here indicate that although stunting prevalence is still higher than overweight in many countries, the difference between the two forms of malnutrition is getting smaller, as demonstrated by the maximum ratio in 2000 (99.85) and the most recent year (46.31). Not only is the decreasing maximum indicative of a move towards the dual burden over time, but the entire range of ratios is shifted closer to 1 , indicating that this is happening across the distribution of countries. These ratios must be interpreted in the context of the overall prevalence. Given a normal distribution of $Z$-scores in a population, we expect $2.5 \%$ of children to have $Z$-scores of -2 and $2.5 \%$ to have $Z$-scores of +2 , producing a ratio of 1 . However, the stunting prevalence is much greater than $2.5 \%$ for all countries in our study and therefore higher than what would be expected for a normally distributed population. For example, the countries with ratios closest to 1 have stunting prevalence in 2000 of $>10 \%$ and overweight prevalence of $>5 \%$. Armenia and Egypt have high rates of both stunting and overweight in both years, whereas Jordan and the Dominican Republic have more moderate rates. Therefore, in these countries we feel confident in our interpretation of the ratio as an indicator of the dual burden and not as an artifact of the normal distribution.

We show that the dual burden of under- and overnutrition also occurs on the individual level. Substantial proportions of children in a country were concurrently stunted and overweight, and stunted children were also overweight, more so in middle- than low-income countries. This occurred alongside the already large numbers of the population who are either stunted or overweight. These instances of individual-level dual burden are particularly troublesome, and similar results have recently been reported among young children in a number of $\mathrm{LMIC}^{(56-58)}$. One explanation is that poor early nutrition (i.e. stunting) may alter physiology to preferentially accumulate fat mass $v$. lean mass ${ }^{(59,60)}$. Poor early nutrition fosters a 'thrifty phenotype' with increased efficiency of fat storage ${ }^{(61)}$, and in utero results in small abdominal viscera and low muscle mass but high levels of $\operatorname{adiposity~}^{(62,63)}$. Stunted children have a greater accumulation of fat mass and a lower lean mass gain when compared with their non-stunted counterparts, and are more likely to deposit fat centrally when entering puberty ${ }^{(59,64)}$. These results may be explained by lower rates of fat oxidation in the stunted children $v$. non-stunted children, or alterations in cortisol metabolism, which may occur in utero or early childhood ${ }^{(65)}$. Stunted children have also exhibited abnormal appetite control and increased energy intake per unit body weight ${ }^{(59,66)}$. Therefore, stunted children lack sufficient nutrients for optimal linear growth, but if they overconsume energy relative to their needs they may preferentially store it as fat. The interventions and approaches needed to identify and optimize the health and nutrition for these distinct segments of the population may be very different.

The present study is not without limitations. First, the selected countries are not globally representative since certain regions are over-represented (Africa) while others are under-represented (Asia). This limits the generalizability of our findings but was a trade-off with our inclusion criteria which ensured we were able to assess trends over time. Our data represent almost three-quarters of a million children from many of the world's regions. Second, in a few countries, the age range differed slightly depending on how each country carried out its DHS (i.e. only children $<3$ years were measured in twelve of 131 country-years, only children $<4$ years were measured in two of 131 country-years). This could give the impression of lower rates in these country-years, as anthropometric deficits tend to accumulate over time. Third, the data were cross-sectional so we cannot make statements about age-specific trends within the same children. Despite these limitations, we believe our results are a valid attempt at quantifying trends in childhood malnutrition and estimating the dual burden. Our results provide a baseline for continued surveillance of global trends.

Recent studies in adults document global shifts in anthropometrics, with many reporting that overweight now exceeds underweight ${ }^{(67-69)}$. Although we show that overweight continues to increase and previous reductions in stunting and wasting have slowed, levels of overweight have not yet surpassed those of stunting or wasting in children $<5$ years. This offers a glimmer of hope that the shift observed in adults is not as severe in young children. We must not be complacent, however, as the dual burden ratio indicates that there are countries with equivalent levels of stunting and overweight and the number is 
increasing. These ratios are likely driven by decreases in stunting, but even in the countries where stunting is still high (e.g. sub-Saharan Africa) we note increases in overweight. We need to be careful of unintentionally increasing overweight when interventions target undernutrition only ${ }^{(54,55)}$.

Childhood undernutrition is decreasing, largely reflecting reductions in stunting. However, these reductions are not consistent across the globe and they are slowing down. Improvements in wasting have stalled, as well. Conversely, overweight continues to increase, which is of great concern. In concert, these individual indicator trends produce a dual burden of malnutrition, both within a population and within the child. Children $<2$ years should be identified as a high-risk demographic and be screened for early intervention. The global nutrition community must continue to engage governments and international agencies to increase efforts to reduce stunting, while simultaneously avoiding overweight.

\section{Acknowledgements}

Acknowledgements: The authors thank Dr Phil Bardsley and Ms Mandy Monath for programming support and Mr Tom Swasey for graphics support. Financial support: This research was supported by an educational grant from Wyeth Nutrition. It also received general support from the Carolina Population Center (R24 HD050924). Wyeth Nutrition and the Carolina Population Center had no role in the design, analysis or writing of this article. Conflict of interest: None. Authorship: E. T. designed the study, acquired the data, analysed and interpreted the data, and drafted the manuscript. M.C.K. assisted in acquiring the data. M.E.B assisted in the study design and provided critical intellectual feedback for the manuscript. L.S.A. assisted in the study design, analysis and interpretation of the data, and provided critical intellectual feedback for the manuscript. All authors have read and approved the final version of the manuscript. Ethics of buman subject participation: This study used publicly available data from DHS. Ethical approval was not required.

\section{Supplementary material}

To view supplementary material for this article, please visit http://dx.doi.org/10.1017/S1368980016000276

\section{References}

1. Black RE, Victora CG, Walker SP et al. (2013) Maternal and child undernutrition and overweight in low-income and middle-income countries. Lancet 382, 427-451.

2. Black RE, Allen LH, Bhutta ZA et al. (2008) Maternal and child undernutrition: global and regional exposures and health consequences. Lancet 371, 243-260.

3. de Onis M, Blössner M \& Borghi E (2012) Prevalence and trends of stunting among pre-school children, 1990-2020. Public Health Nutr 15, 142-148.
4. Popkin BM (1994) The nutrition transition in low-income countries: an emerging crisis. Nutr Rev 52, 285-298.

5. Onis M de, Blössner M \& Borghi E (2010) Global prevalence and trends of overweight and obesity among preschool children. Am J Clin Nutr 92, 1257-1264.

6. Doak CM, Adair LS, Bentley M et al. (2005) The dual burden household and the nutrition transition paradox. Int $J$ Obes (Lond) 29, 129-136.

7. Shrimpton R \& Rokx C (2012) The Double Burden of Malnutrition: A Review of Global Evidence. Health, Nutrition and Population (HNP) Discussion Paper. Washington, DC: World Bank.

8. Gillespie SR \& Haddad LJ (2003) The Double Burden of Malnutrition in Asia: Causes, Consequences, and Solutions. New Delhi: Sage Publications India Pvt Limited.

9. World Health Organization (1995) Physical Status: The Use and Interpretation of Anthropometry. Report of a WHO Expert Committee. WHO Technical Report Series no. 854. Geneva: WHO.

10. Department of Economic and Social Affairs (2000) Underweight prevalence among preschool children. In Charting the Progress of Populations, pp. 27-31. New York: United Nations Population Division.

11. 1,000 Days (2010) 1,000 Days. http://thousanddays.org/ (accessed September 2012).

12. Mendez MA \& Adair LS (1999) Severity and timing of stunting in the first two years of life affect performance on cognitive tests in late childhood. J Nutr 129, 1555-1562.

13. Slining MM, Herring AH, Popkin BM et al. (2013) Infant BMI trajectories are associated with young adult body composition. J Dev Orig Health Dis 4, 56-68.

14. Victora CG, Adair L, Fall C et al. (2008) Maternal and child undernutrition: consequences for adult health and human capital. Lancet 371, 340-357.

15. Singh AS, Mulder C, Twisk JWR et al. (2008) Tracking of childhood overweight into adulthood: a systematic review of the literature. Obes Rev $9,474-488$.

16. Adair LS, Fall CHD, Osmond C et al. (2013) Associations of linear growth and relative weight gain during early life with adult health and human capital in countries of low and middle income: findings from five birth cohort studies. Lancet 382, 525-534.

17. Onis M de \& Blössner M (2000) Prevalence and trends of overweight among preschool children in developing countries. Am J Clin Nutr 72, 1032-1039.

18. Jinabhai CC, Taylor M \& Sullivan KR (2005) Changing patterns of under- and over-nutrition in South African children - future risks of non-communicable diseases. Ann Trop Paediatr 25, 3-15.

19. Cattaneo A, Timmer A, Bomestar T et al. (2008) Child nutrition in countries of the Commonwealth of Independent States: time to redirect strategies? Public Health Nutr 11, 1209-1219.

20. Motlagh ME, Kelishadi R, Amirkhani MA et al. (2011) Double burden of nutritional disorders in young Iranian children: findings of a nationwide screening survey. Public Health Nutr 14, 605-610.

21. Ferreira H da S \& Luciano SCM (2010) Prevalence of extreme anthropometric measurements in children from Alagoas, Northeastern Brazil. Rev Saude Publica 44, 377-380.

22. Gardner K, Bird J, Canning PM et al. (2011) Prevalence of overweight, obesity and underweight among 5-year-old children in Saint Lucia by three methods of classification and a comparison with historical rates. Child Care Health Dev 37, 143-149.

23. Jafar TH, Qadri Z, Islam M et al. (2008) Rise in childhood obesity with persistently high rates of undernutrition among 
urban school-aged Indo-Asian children. Arch Dis Child $\mathbf{9 3}$ 373-378.

24. Wang X, Höjer B, Guo S et al. (2009) Stunting and 'overweight' in the WHO Child Growth Standards - malnutrition among children in a poor area of China. Public Health Nutr 12, 1991-1998.

25. Kimani-Murage EW, Kahn K, Pettifor JM et al. (2010) The prevalence of stunting, overweight and obesity, and metabolic disease risk in rural South African children. $B M C$ Public Health 10, 158.

26. Corsi DJ, Neuman M, Finlay JE et al. (2012) Demographic and health surveys: a profile. Int J Epidemiol 41, 1602-1613.

27. MEASURE DHS (2011) Methodology. http://www. measuredhs.com/What-We-Do/Methodology.cfm （accessed November 2013).

28. WHO Multicentre Growth Reference Study Group (2006) WHO Child Growth Standards based on length/height, weight and age. Acta Paediatr 450, 76-85.

29. World Bank (2010) Data. GNI per capita, Atlas method (current US\$). Table. http://data.worldbank.org/indicator/ NY.GNP.PCAP.CD/countries (accessed November 2013).

30. World Health Organization (2006) WHO Anthro (version 3.2.2, January 2011) and macros. http://www.who.int/ childgrowth/software/en/ (accessed June 2013).

31. National Population Commission (2000) Nigeria Demographic and Health Survey 1999. Calverton, MD: National Population Commission and ORC/Macro.

32. United Nations (2008) Millennium Development Goals. http://www.un.org/millenniumgoals/bkgd.shtml (accessed May 2014).

33. Loret de Mola C, Quispe R, Valle GA et al. (2014) Nutritional transition in children under five years and women of reproductive age: a 15 -years trend analysis in Peru. PLOS One 9, e92550.

34. Ramos CV, Dumith SC \& César JA (2015) Prevalence and factors associated with stunting and excess weight in children aged $0-5$ years from the Brazilian semi-arid region. J Pediatr (Rio J) 91, 175-182.

35. Das SK, Chisti MJ, Malek MA et al. (2015) Changing childhood malnutrition in Bangladesh: trends over the last two decades in urban-rural differentials (1993-2012). Public Health Nutr 18, 1718-1727.

36. Stevens GA, Finucane MM, Paciorek CJ et al. (2012) Trends in mild, moderate, and severe stunting and underweight, and progress towards MDG 1 in 141 developing countries: a systematic analysis of population representative data. Lancet 380, 824-834.

37. Urke HB, Bull T \& Mittelmark MB (2011) Socioeconomic status and chronic child malnutrition: wealth and maternal education matter more in the Peruvian Andes than nationally. Nutr Res 31, 741-747.

38. Kanjilal B, Mazumdar PG, Mukherjee M et al. (2010) Nutritional status of children in India: household socio-economic condition as the contextual determinant. Int J Equity Health 9, 19.

39. Matijasevich A, Santos IS, Menezes AMB et al. (2012) Trends in socioeconomic inequalities in anthropometric status in a population undergoing the nutritional transition: data from 1982, 1993 and 2004 Pelotas birth cohort studies. BMC Public Health 12, 511.

40. Monyeki MA, Awotidebe A, Strydom GL et al. (2015) The challenges of underweight and overweight in South African children: are we winning or losing the battle? A systematic review. Int J Environ Res Public Health $\mathbf{1 2}$, $1156-1173$

41. Victora CG \& Rivera JA (2014) Optimal child growth and the double burden of malnutrition: research and programmatic implications. Am J Clin Nutr 100, issue 6, 1611S-1612S.
42. Barker DJP, Bergmann RL \& Ogra PL (2008) Concluding remarks. The window of opportunity: pre-pregnancy to 24 months of age. Nestlé Nutr Workshop Ser Paediatr Program 61, 255-260.

43. Lundeen EA, Stein AD, Adair LS et al. (2014) Height-for-age z scores increase despite increasing height deficits among children in 5 developing countries. Am J Clin Nutr 100, 821-825.

44. Shrimpton R, Victora CG, de Onis M et al. (2001) Worldwide timing of growth faltering: implications for nutritional interventions. Pediatrics 107, E75.

45. Okihiro M, Davis J, White L et al. (2012) Rapid growth from 12 to 23 months of life predicts obesity in a population of Pacific Island children. Ethn Dis 22, 439-444.

46. Chomtho S, Wells JC, Williams JE et al. (2008) Infant growth and later body composition: evidence from the 4-component model. Am J Clin Nutr 87, 1776-1784.

47. Dennison BA, Edmunds LS, Stratton HH et al. (2006) Rapid infant weight gain predicts childhood overweight. Obesity (Silver Spring) 14, 491-499.

48. Druet C, Stettler N, Sharp S et al. (2012) Prediction of childhood obesity by infancy weight gain: an individuallevel meta-analysis. Paediatr Perinat Epidemiol 26, $19-26$.

49. Taveras EM, Rifas-Shiman SL, Belfort MB et al. (2009) Weight status in the first 6 months of life and obesity at 3 years of age. Pediatrics 123, 1177-1183.

50. Monteiro POA \& Victora CG (2005) Rapid growth in infancy and childhood and obesity in later life - a systematic review. Obes Rev 6, 143-154.

51. González DA, Nazmi A \& Victora CG (2010) Growth from birth to adulthood and abdominal obesity in a Brazilian birth cohort. Int J Obes (Lond) 34, 195-202.

52. McCormick DP, Sarpong K, Jordan L et al. (2010) Infant obesity: are we ready to make this diagnosis? J Pediatr 157, 15-19.

53. Victora CG \& Barros FC (2001) Commentary: The catch-up dilemma - relevance of Leitch's 'low-high' pig to child growth in developing countries. Int J Epidemiol 30, 217-220.

54. Fernald LCH, Gertler PJ \& Hou X (2008) Cash component of conditional cash transfer program is associated with higher body mass index and blood pressure in adults. J Nutr 138, $2250-2257$.

55. Uauy R \& Kain J (2002) The epidemiological transition: need to incorporate obesity prevention into nutrition programmes. Public Health Nutr 5, 223-229.

56. Freire WB, Silva-Jaramillo KM, Ramírez-Luzuriaga MJ et al. (2014) The double burden of undernutrition and excess body weight in Ecuador. Am J Clin Nutr 100, issue 6, 1636S-1643S.

57. Kroker-Lobos MF, Pedroza-Tobías A, Pedraza LS et al. (2014) The double burden of undernutrition and excess body weight in Mexico. Am J Clin Nutr 100, issue 6, 1652S-1658S.

58. Ramirez-Zea M, Kroker-Lobos MF, Close-Fernandez R et al. (2014) The double burden of malnutrition in indigenous and nonindigenous Guatemalan populations. Am J Clin Nutr 100, issue 6, 1644S-1651S.

59. Martins PA, Hoffman DJ, Fernandes MTB et al. (2004) Stunted children gain less lean body mass and more fat mass than their non-stunted counterparts: a prospective study. Br J Nutr 92, 819-825.

60. Long NM, George LA, Uthlaut AB et al. (2010) Maternal obesity and increased nutrient intake before and during gestation in the ewe results in altered growth, adiposity, and glucose tolerance in adult offspring. J Anim Sci 88, 3546-3553.

61. Dulloo AG (2006) Regulation of fat storage via suppressed thermogenesis: a thrifty phenotype that predisposes 
individuals with catch-up growth to insulin resistance and obesity. Horm Res 65, Suppl. 3, 90-97.

62. Yajnik CS, Fall CHD, Coyaji KJ et al. (2003) Neonatal anthropometry: the thin-fat Indian baby. The Pune Maternal Nutrition Study. Int J Obes Relat Metab Disord 27, 173-180.

63. Muthayya S, Dwarkanath P, Thomas T et al. (2006) Anthropometry and body composition of south Indian babies at birth. Public Health Nutr 9, 896-903.

64. Hoffman DJ, Martins PA, Roberts SB et al. (2007) Body fat distribution in stunted compared with normal-height children from the shantytowns of São Paulo, Brazil. Nutrition 23, 640-646.

65. Hoffman DJ, Sawaya AL, Verreschi I et al. (2000) Why are nutritionally stunted children at increased risk of obesity? Studies of metabolic rate and fat oxidation in shantytown children from São Paulo, Brazil. Am J Clin Nutr 72, 702-707.
66. Hoffman DJ, Roberts SB, Verreschi I et al. (2000) Regulation of energy intake may be impaired in nutritionally stunted children from the shantytowns of São Paulo, Brazil. $J$ Nutr 130, 2265-2270.

67. Popkin BM \& Slining MM (2013) New dynamics in global obesity facing low- and middle-income countries. Obes Rev 14, Suppl. 2, 11-20.

68. Razak F, Corsi DJ \& Subramanian SV (2013) Change in the body mass index distribution for women: analysis of surveys from 37 low- and middle-income countries. PLoS Med 10, e1001367.

69. Jones-Smith JC, Gordon-Larsen P, Siddiqi A et al. (2011) Cross-national comparisons of time trends in overweight inequality by socioeconomic status among women using repeated cross-sectional surveys from 37 developing countries, 1989-2007. Am J Epidemiol 173, 667-675. 